\title{
CONTINUIDAD Y CAMBIO DURANTE EL SIGLO VI A.C. LAS CERÁMICAS DEL CORTE C DEL CERRO MACARENO (LA RINCONADA, SEVILLA)
}

\author{
CONTINUITY AND CHANGE DURING THE $6^{\text {TH }}$ CENTURY BC: POTTERY \\ FROM TEST-PIT C OF CERRO MACARENO (LA RINCONADA, SEVILL)
}

\author{
por \\ DIEGO RUIZ MATA y \\ JUAN IGNACIO VALLEJO SÁNCHEZ*
}

RESUMEN En la campaña de excavaciones de 1974 se practicaron diversos sondeos en el yacimiento protohistórico del Cerro Macareno. Uno de ellos, el corte C, inédito hasta la fecha, ofreció un interesante conjunto de cerámicas que recogían la mayor parte del repertorio típico del siglo VI a.C. Su estudio, además de completar la información disponible sobre el asentamiento, aporta interesantes datos sobre la continuidad y el cambio que se aprecian en la cerámica, en un momento tan crucial y "crítico" como es el siglo VI a.C.

\begin{abstract}
During the excavations campaign of 1974 several test drillings were made in the protohistorical site of "Cerro Macareno". One of them, hitherto unknown, the "c" section, offered an interesting set of pottery which gathered together most of the typical $6^{\text {th }}$ B.C. repertoire. Its study, apart from completing the information available about the settlement, contributes interesting data on the continuity and the change that can be seen in the pottery in such a crucial and critical moment as the $6^{\text {th }}$ B.C.
\end{abstract}

Palabras claves Cerro Macareno. Cerámicas Protohistóricas. "Crisis" del siglo VI a.C.

Key words Cerro Macareno. Protohistorical Pottery. $6^{\text {th }}$ B.C. crisis.

El yacimiento del Cerro Macareno constituye, desde la década de los ochenta, uno de los hitos bibliográficos y cronológicos de la Protohistoria del sur de la Península Ibérica. La memoria redactada por Manuel Pellicer y su equipo en 1983 (Pellicer et al. 1983) así como otros trabajos publicados en revistas y congresos (Martín de la Cruz 1976; Fernández Gómez et al. 1979; Pellicer 1979; Id. 1982; Amberger 1985; etc.) sirvieron

\footnotetext{
* Área de Prehistoria, Universidad de Cádiz.
} 
y aún sirven como referente imprescindible en los estudios de cerámica protohistórica desarrollados desde entonces ${ }^{1}$. La búsqueda de la cronología, del tiempo histórico, fue la principal preocupación de la Arqueología protohistórica andaluza en aquellos años de aprendizaje y conocimientos incipientes. La práctica de sondeos estratigráficos que revelasen la enrevesada secuencia protohistórica y que proporcionasen fósiles-guía que permitiesen una contextualización de los hallazgos se convirtieron en la práctica común de la investigación (Escacena 2000: 94-103; Pellicer 1995).

Con este trabajo nuestra intención es aportar nuevos datos sobre el conjunto de este yacimiento, a cuyo conocimiento tanto contribuyó el Profesor Manuel Pellicer, a quien desde estas líneas queremos rendir nuestro más sincero homenaje.

De entre las numerosas excavaciones que se practicaron en el Cerro Macareno, algunas de ellas aún no han sido publicadas. A pesar de los años transcurridos, los datos que nos aporta este yacimiento siguen teniendo un considerable interés, pues los materiales arqueológicos del denominado corte "C $\mathrm{C}$ ", de los que nos ocupamos en este artículo, pertenecen a un momento decisivo de la Protohistoria del Suroeste, el siglo VI a.C., durante el que tienen lugar una serie de cambios muy significativos en las estructuras socioeconómicas y políticas Tartessos y que conducirían a la formación del mundo turdetano.

\section{LA HISTORIA DE LA INVESTIGACIÓN}

Por Cerro Macareno conocemos a unas suaves lomas que se elevan sobre la campiña sevillana, dentro del término municipal de La Rinconada ${ }^{2}$ (Fig. 1). Actualmente deshabitado, el cerro se ocupó durante época protohistórica, desde la segunda mitad del siglo VIII a principios del siglo II a.C. (Pellicer et al. 1983: 107-109).

La historia de su descubrimiento e investigación se vincula, como en tantos otros casos, con la de su propia destrucción. Las primeras noticias que tenemos del valor arqueológico de esta colina se remontan a principios de los años setenta, cuando unos vecinos de Brenes, población situada a unos $10 \mathrm{~km}$ al noreste de La Rinconada, comunican la existencia de materiales arqueológicos en la zona al Departamento de Prehistoria y Arqueología de la Universidad de Sevilla. Desde entonces se han venido desarrollando en el lugar una serie de trabajos de investigación.

Las prospecciones superficiales realizadas en 1971 por D. Ángel Cuenca Anaya (Pellicer et al. 1983: 15) permitieron establecer el área estimada de extensión del yacimiento arqueológico, haciendo posible más adelante la planificación de los cortes a realizar, su número y la selección de zonas que a priori ofrecían un mayor interés.

La devastación de la que estaba siendo objeto el yacimiento, debido a su utilización para la extracción de áridos, que ponía en peligro no ya su integridad, seriamente afectada, sino incluso su propia existencia, animó a la Administración a declararlo de utilidad pública a finales de 1973, con la pretensión de expropiarlo en un futuro. Pero esta destrucción sistemática no se interrumpió hasta 1975, cuando definitivamente se pusieron en marcha los trámites para incoar expediente de expropiación (Pellicer et al. 1983: 15).

Las primeras campañas de excavaciones, proyectadas por iniciativa del Comisario Nacional de Excavaciones Arqueológicas, cargo ejercido entonces por el Prof. Maluquer, tuvieron lugar en el año 1974. En otoño se platearon varios cortes en los cuadros H.I, H.II, G y F, situados en una zona parcialmente destruida por las palas mecánicas, en la que afloraban restos de viviendas y se había recogido un número considerable

1. Además de la bibliografía citada, la producción generada a partir de las investigaciones desarrolladas en el yacimiento se amplia con diversos artículos y noticias en revistas especializadas, de diverso alcance (Fernández Chicarro 1976), así como comunicaciones presentadas a congresos que no llegaron a publicarse (Pellicer y Bendala 1976; Pellicer 1979).

2. El yacimiento se localiza en las coordenadas geográficas $2^{\circ} 16^{\prime} 25^{\prime \prime}$ longitud, $37^{\circ} 28^{\prime} 40^{\prime \prime}$ latitud, hoja 984 del mapa 1:50.000 del Mapa Militar de España 
de materiales cerámicos (Fig. 1). En verano se realizaron las excavaciones de los cortes A, B y C, ubicados en el sector B, de acuerdo con la zonificación que establecieron Pellicer y su equipo (Pellicer et al. 1983: 18; fig. 3).

Tras el paréntesis de 1975, año en el que a pesar de haberse proyectado la realización de excavaciones diversas circunstancias impidieron su puesta en práctica (Pellicer et al. 1983: 15-16), en 1976 el equipo dirigido por el Prof. Pellicer excavó el denominado corte V/20, situado en la zona A, es decir, en el extremo más suroriental del yacimiento y que ofreció la única secuencia estratigráfica completa del poblamiento (Pellicer et al. 1983: 18 ss.) (Fig. 1).

Una de las particularidades de la investigación en el Cerro Macareno es el haber reunido a profesionales de distintas instituciones y procedencias geográficas. Las principales aportaciones proceden de la Universidad de Sevilla, el Museo Arqueológico Provincial hispalense y la Universidad Complutense de Madrid. La dirección de los distintos equipos ha estado encomendada principalmente a los profesores Sánchez Meseguer (corte C), Fernández Gómez (cortes E, F y G), Ruiz Mata (cortes H.I y H.II. Posteriormente se hizo cargo de los cortes A, B y C) y Pellicer (corte V/20), entre otros (Ramón Corzo, Salvador de Sacha).

Tras la parcial destrucción del yacimiento y la interrupción de los trabajos en el mismo, una parte importante de los resultados de la investigación fueron publicados. El llamado corte V/20 es sin duda uno de los más divulgados en la bibliografía, tanto a nivel nacional (Pellicer 1976-78; Id. 1978; Id. 1979; Id. 1980; Pellicer et al. 1983), como internacional (Pellicer 1982; Amberger 1985). Los cortes E y G fueron publicados a finales de los setenta por el director del equipo (Fernández Gómez et al. 1979), como también hizo parcialmente con el corte $\mathrm{F}(\mathrm{Ib}$.), cuyos materiales fueron objeto de estudio de una Memoria de Licenciatura (Martín de la Cruz 1975 y 1976). Sin embargo, otros sectores no se conocen tan bien, como los cortes A y B, que permanecen inéditos hasta el momento, los cortes H.I y H.II, que han visto recientemente la luz en una comunicación presentada al XXIV Congreso Nacional de Arqueología (Ruiz Mata y Córdoba 1999). Finalmente, el corte $\mathrm{C}$, sin publicar hasta el momento, y que ahora presentamos ${ }^{3}$.

\section{LA EXCAVACIÓN DEL CORTE C}

El corte $\mathrm{C}$, junto a los denominados $\mathrm{A}$ y $\mathrm{B}$, se practicó con la finalidad de explorar un área del yacimiento que se estaba viendo seriamente afectada por las destrucciones sistemáticas de las palas mecánicas y por los desplomes frecuentes en los límites del sector. Se pretendía obtener una visión de la estratigrafía del poblado -aunque ésta fuese incompleta, pues la colina había sufrido ya un rebaje en su potencia de unos cinco metros-de acuerdo a las estimaciones hechas a partir de las excavaciones del corte V/20. Se buscaba, pues, salvaguardar en la medida de lo posible la información arqueológica restante y, además, documentar los niveles más antiguos del asentamiento.

Se planteó un cuadro de tres por tres metros, quedando uno de sus lados en la misma vertiente de la ladera, que ofreció una estratigrafía de 2' 5 metros de potencia máxima (Fig. 2), donde podían distinguirse claramente tres estratos, numerados como niveles I, II y III, por orden de deposición. No se constató la presencia de restos constructivos, ni tampoco otros materiales distintos a los cerámicos. Estos apenas presentaban grandes diferencias de conjunto entre sí. Y podemos datarlos globalmente en torno al siglo VI a.C., como puede desprenderse del análisis realizado, que a continuación resumimos.

3. Un estudio preliminar de la cerámica del corte C fue presentado como comunicación al XXIV Congreso Nacional de Arqueología (Cartagena, 1997), aunque el texto no fue finalmente entregado para su publicación en las actas. 


\section{LAS CERÁMICAS DEL CORTE C}

La relativa homogeneidad de las cerámicas aparecidas en esta excavación aconsejan su análisis global, sin que la distingamos por niveles. El conjunto se compone de un reducido número de individuos, que no superan las tres centenas. La gran mayoría de las cerámicas estudiadas son a torno, aunque no faltan las vasijas a mano, que son las predominantes en el nivel más antiguo (Fig. 2). Cronológicamente, las cerámicas se encuadran entre finales del siglo VII y finales del siglo VI o inicios del V a.C.

\subsection{Las cerámicas a mano}

La mayor parte de estas cerámicas se concentran en el estrato I, correspondientes a la fase orientalizante del poblado, de acuerdo con la periodización propuesta por Pellicer (Pellicer et al. 1983: 107-109, fig. 16), con una cronología, para los materiales que nos ocupan, de finales del siglo VII y principios del VI a.C. También encontramos estas cerámicas en los estratos II y III, aunque en proporción decreciente, llegando a ser su presencia meramente testimonial en el último nivel (Gráf.1).

La utilización de cerámicas realizadas a mano es común en los yacimientos protohistóricos de esta época, sobre todo en la vajilla de cocina y en la destinada al consumo de alimentos. Siguen la tradición propia del Bronce Final de Andalucía Occidental, conviviendo con otras cerámicas realizadas a torno y empleadas para usos domésticos, como las cerámicas grises orientalizantes, o diversas formas de mesa fabricadas en pastas claras, o con usos de almacenamiento - pithoi-, transporte -ánforas- y otros -lebrillos, etc.-.

\subsubsection{Vasos utilizados para el consumo de alimentos}

Incluimos en este apartado un numeroso grupo de formas abiertas, cazuelas o platos, que se asocian generalmente al consumo de alimentos (Gráf. 1). Algunos ejemplares presentan el borde ligeramente exvasado, rematado por un labio simple, y diferenciado del cuerpo, presumiblemente hemisférico, por una carena más o menos suave (Fig. 3, 1-4). Guardan gran similitud con el tipo A.II.a. de Ruiz Mata, quien propone una cronología del siglo VII a.C. para estos vasos (Ruiz Mata 1995 b: 273).

Uno de los cuencos de esta forma, hallado en el estrato II, presenta en su superficie interior decoración de motivos geométricos bruñidos (Fig. 3, 4). Los motivos, lazos o bucles que alternan con una retícula, están bruñidos sobre espacios en reserva, que estarían delimitados por un aspa igualmente bruñida que organiza todo el esquema decorativo -como es usual en las decoraciones análogas que encontramos en todo el Bajo Guadalquivir (López Roa 1977; Id. 1978)-. Este tipo de decoración es característico de la cerámica a mano del Bronce Final, particularmente en el Bajo Guadalquivir (López Roa 1977; Id. 1978; Ruiz Mata 1995 b: 280-281; Gómez Toscano 1997: 234-235), perdurando hasta el siglo VI a.C. y utilizándose incluso en producciones a torno, como las cerámicas grises orientalizantes (Vallejo 2000).

Quizás relacionadas con otras actividades ligadas al consumo o a la preparación de los alimentos podamos considerar a los vasos carenados de cuello alto y exvasados, de perfiles exteriores cóncavos (Fig. 3, 9). Corresponderían, grosso modo, con el tipo VII de la fase II del poblado Bajo del Carambolo, fechada en pleno siglo VII a.C. (Ruiz Mata 1995 b: 274; fig. 17, 25). A conclusiones cronológicas parecidas se llega en el corte $\mathrm{V} / 20$, donde en el nivel 23 aparece un ejemplar similar, diferenciado como forma 9 y datado por sus excavadores a mediados del siglo VII a.C. (Pellicer et al. 1983: 67; fig. 76, 9), aunque el ejemplar del corte $\mathrm{C}$ presenta unas dimensiones sensiblemente menores. 
Por último, los cuencos de bordes simples y cuerpos semiesféricos aparecen en contextos del siglo VII a.C. en todo el yacimiento, no sólo en el corte C (Fig. 3, 5-8), sino también en el V/20, al menos desde el siglo VII a.C. (Pellicer et al. 1983: 70; fig. 78, 2-4), presentando uno de nuestros ejemplares pequeños mamelones aplicados sobre el borde (Fig. 3, 5).

\subsubsection{Vasos para la transformación de alimentos}

Dentro de esta categoría incluimos, en primer lugar, las llamadas "ollas", con cuerpo de tendencia globular, bases planas y gruesas, bordes ligeramente exvasados, de altura variable, que presentan en los hombros una característica decoración a base de impresiones digitadas o similares y que en ocasiones tienen un asa semicircular que une borde y cuerpo (Fig. 3,10-12). De superficies toscas, rugosas, confeccionadas a partir de pastas groseras y mínimamente tratadas, estas ollas corresponden al tipo G.II de Ruiz Mata (Ruiz Mata 1995 b: 278-279; fig. 25). Se trata de una forma muy común en todo el Bajo Guadalquivir (Ladrón de Guevara 1994) y entre las formas recogidas en el corte $C$ es una de las más numerosas de todo el conjunto de las cerámicas a mano en el estrato I y, especialmente, en el II (Gráf. 1). Los ejemplares más antiguos de esta forma con decoración digitada las documentamos en el Cabezo de San Pedro, en la fase IB (Blázquez et al. 1979: 134-135; Ruiz Mata et al. 1981: 241) y en el fondo V de San Bartolomé -Almonte, Huelva-(Ruiz Mata y Fernández-Jurado 1986: 55; lám. XXV, 345), en la segunda mitad o comienzos del siglo VIII a.C., aunque empiezan a utilizarse con mayor frecuencia hacia finales del siglo VIII y sobre todo en la centuria siguiente (Ruiz Mata 1995 b: 279).

Estas mismas ollas se fabrican también con formas muy similares, pero sin decoración alguna (Fig. 3, 13-14), o con otras decoraciones plásticas, menos usuales, como mamelones u otros apliques (Fig. 3, 15).

\subsubsection{Vasos de almacenaje}

Entre las vasijas de gran capacidad, destacan las urnas con cuerpo de tendencia cónica, de borde exvasado separado por una carena acusada (Fig. 3, 20). Se corresponden con las urnas del tipo C del túmulo B de Setefilla, con una cronología estimada de siglo VII a.C. (Ruiz Mata 1995 b: 278; fig. 23, 7; Aubet 1978: 175; fig. 7, 2). Similar, en contexto estratigráfico y en morfología, es el vaso de la Fig. 3, 19, aunque éste presenta un borde más corto y un cuerpo globular más cercano al de las ollas.

Contamos con varios ejemplares de los denominados vasos "à chardon" (Gráf. 1), de cuerpo globular y bordes altos, exvasados (Fig. 3, 18). Suelen presentar el cuello bruñido o alisado, el cuerpo carece de cualquier tratamiento especial y presenta las superficies rugosas. Se corresponde al tipo E.II de Ruiz Mata (Ruiz Mata 1995 b: 277-278; figs. 22-24). La cronología de los primeros ejemplares se puede remontar al siglo VIII a.C..(Aubet 1978; Ruiz Mata y Pérez 1989: 291; Córdoba y Ruiz Mata 2000; Torres 1996), aunque es una forma que se usa aún con frecuencia en el siglo VII a.C. En el Cerro Macareno, además de en el corte $C$ y en superficie (Fernández Gómez et al. 1979: 62-63; fig. 38), aparece entre las cerámicas del corte V/20, equivalente a la forma 5 de Pellicer, desde el nivel 26, fechado a finales del siglo VIII, al nivel 21, de finales del VII a.C. (Pellicer et al. 1983: 65; fig. 76). 


\subsubsection{Otras formas}

Aunque sólo contamos con un ejemplar, nos parece oportuno por su especial significado mencionar un vaso perforado o colador hallado en el estrato II (Fig. 3, 22). Responde a las características generales de las vasijas de este tipo: fabricadas en pastas groseras y de superficies toscas, con gruesas paredes perforadas por pequeños orificios. Se corresponden con el tipo H.II de Ruiz Mata (Ruiz Mata 1995 b: 279, fig. 27, 1-3) y suelen asociarse a actividades metalúrgicas, concretamente al proceso de copelación de la plata (Ruiz Mata 1989: 227, fig. 11). Aparecen desde el siglo VIII a.C. en numerosos yacimientos del Suroeste, especialmente en las zonas minero-metalúrgicas (Ruiz Mata 1995 b: 271, 279; Ruiz Mata 1981: 159). En el Cerro Macareno además de en el corte C, están presentes en los niveles 25 y 26 del corte V/20, con una cronología de finales del siglo VIII e inicios del VII a.C. (Pellicer et al. 1983: 68, figs. 76, 10-11).

El estado fragmentario que presenta el resto del conjunto dificulta un análisis más pormenorizado de las formas. No obstante, merece la pena mencionar la presencia de algunos bordes de vasos cerrados, probablemente con cuerpos de tendencia globular u ovoide (Fig. 3, 16-17); o un fragmento con decoración de líneas incisas, perteneciente probablemente a un vaso cerrado (Fig. 3, 21).

\subsection{Cerámica a torno}

Las vasijas fabricadas a torno son las más abundantes entre los materiales recuperados del corte $\mathrm{C}$, concentrándose la mayoría de ellas en los estratos II y III, observándose una notable variedad de formas y de tratamientos técnicos y decorativos (Gráf. 2). Distinguimos los tres grandes grupos convencionales en la exposición de las formas, de acuerdo a las funciones que generalmente se les atribuyen: las vasijas destinadas al transporte, las utilizadas para el almacenamiento y aquéllas empleadas para el procesamiento y el consumo de alimentos, así como otros usos relacionados con la transformación de materias primas.

\subsubsection{Las ánforas}

Las ánforas constituyen una de las formas cerámicas más abundantes en el Cerro Macareno, a juzgar por los resultados de los cortes V/20 (Pellicer et al. 1983: 84 ss.), E, F y G (Fernández Gómez et al. 1979: 46-49; Martín de la Cruz 1976), H.I y H.II (Ruiz Mata y Córdoba 1999). En el corte C, sin embargo, contamos únicamente con un mínimo porcentaje de ejemplares (Gráf. 2) pertenecientes en su mayoría a las formas A y B de Pellicer, de acuerdo a la tipología establecida a partir de los materiales del propio yacimiento (Pellicer 1978; Id. 1982: 388-396; Florido 1984).

La primera de las formas, evolución de las tradicionales R-1, presenta un borde corto, recto y vertical en su cara exterior y engrosado en la interior, mostrando una sección triangular con los vértices redondeados (Fig. 4, 1-2). Los hombros son de tendencia semiesférica, diferenciados del cuerpo-probablemente ovoidalpor una fuerte carena; siendo las asas tubulares o de orejeta. En el propio Cerro Macareno aparecen a finales del siglo VII a.C. (Pellicer 1982: 388), coincidiendo con las cronologías propuestas para esta forma en el Mediterráneo Occidental (Ramón 1995).

Producto igualmente de la evolución de las ánforas R-1 es la forma B de Pellicer, incluida entre las denominadas ibero-púnicas (Fig. 4, 3). Presenta un borde ex vasado -más o menos grueso- y hombros redondeados. Aparece en el Cerro Macareno desde principios del siglo VI a.C. (Pellicer 1982: 390).

Mención especial merece un ánfora localizada en el estrato III del corte C. Morfológicamente se caracteriza por su borde exvasado, hombros redondeados unidos al cuerpo, de tendencia cilíndrica, por una 
suave curvatura de la que arranca un asa circular (Fig. 4,4). Su principal interés radica en el hecho de estar decorada al exterior por bandas horizontales pintadas en tonos anaranjados y rojos violáceos que componen, con toda probabilidad, el marco superior de una franja cubierta de bandas pintadas verticalmente en los mismos colores. Piezas similares, en técnica decorativa y composiciones y en forma-aunque con el hombro netamente separado del cuerpo por una carena- las encontramos en el corte B-5 de Tejada la Vieja (Fernández Jurado 1987, II: 52-53, lám. XXIII, 1), con una cronología estimada del siglo VI a.C. (Ib., I: 103-104); así como en el propio Cerro Macareno, entre los siglos V y IV a.C. (Fernández Gómez et al. 1979: fig. 41, 400: 59), por citar algunos ejemplos (Belén y Pereira 1985: 326-327, fig. 11).

\subsubsection{Los vasos destinados a almacenamiento}

La primera forma que tratamos dentro de esta categoría corresponde a vasos de cuerpos de tendencia ovalada, cuellos troncocónicos abiertos, de paredes exvasadas, ligeramente acampanadas, con una moldura central (Fig. 5, 1). Los bordes, abiertos al exterior, muestran a menudo una sección en pestaña. Los diámetros de apertura de las bocas oscilan, en el caso de los ejemplares hallados en el corte C, entre los $10 \mathrm{y} l o s 12 \mathrm{~cm}$. Presumiblemente, estas vasijas presentaban asas geminadas que arrancan del baquetón central del cuello y descansan sobre el hombro, como puede apreciarse en algunas piezas de las aquí estudiadas (Fig. 5, 1). Esta forma supone una evolución de las denominadas urnas tipo "Cruz del Negro" presentes en los yacimientos orientalizantes andaluces en los siglos VIII y, sobre todo, VII a.C., y que perdura a lo largo del siglo VI a.C. Los cambios tipológicos más apreciables consisten en la tendencia ovoidal de los cuerpos, frente a la globular de los ejemplares antiguos, el cuello más abierto e inclinado y un borde menos apuntado (Ruiz Mata 1987: 306). Esta forma, habitual en los yacimientos andaluces de este período (Ruiz Mata y Pérez Pérez 1995: 70; Aubet et al. 1999: 173-177), no parece, sin embargo, frecuente entre los materiales del Cerro Macareno (Pellicer et al. 1983: 94-96, fig. 104).

Cercanos a éstos en la forma son los vasos de la Fig. 5, 2-3, aunque presentan bocas con una mayor apertura y no cuentan con la característica moldura central.

Mayores dimensiones y capacidades encontramos en otros vasos (Fig. 5, 4-5), de cuellos abocinados, bordes exvasados y engrosados, que muestran una sección ovalada, con diámetros de boca en torno a los 18-20 cm y con cuerpos de tendencia ovoidal. Esta forma enraíza, nuevamente, en el siglo VII a.C., hallándose diversas variantes de la misma en el mismo Cerro Macareno entre este siglo y el V a.C. en el corte V/20 (Pellicer et al. 1983: 94-95, fig. 104) y alrededor de los siglos V-IV a.C. en los cortes E-F-G (Fernández Gómez et al. 1979: 29-33).

Todas estas formas suelen estar decoradas con bandas y líneas pintadas en la superficie exterior de cuellos y bordes (Fig. 5, 6-12) -también en el interior, en la zona más próxima a éstos-, así como en el cuerpo de la vasija, con las mismas bandas y líneas horizontales polícromas, combinadas en ocasiones con líneas verticales (Fig. 5, 6, 7 y 9) o círculos (Fig. 5, 8 y10) y diversos motivos que aparecen en vasos de grandes dimensiones (Fig. 5, 11-12). Estas decoraciones suelen aplicarse sobre las superficies claras de las cerámicas, recubiertas muchas veces por un engobe blanquecino que mejora la adhesión de los colores aplicados-distintas tonalidades de negros y rojos-.

Además de en estas formas, encontramos este tipo de decoraciones polícromas en ánforas (Fig. 4, 4), en un solo caso; en los cuencos, frecuentemente monócromas, como veremos más adelante, pintados al interior y con una banda señalando exteriormente el labio del mismo, en tonos ocres (Fig. 6, 6-7); en los lebrillos, con bandas de distinto grosor principalmente al exterior, pero también presentes en el interior, y pinceladas de color-siempre en tonos ocres y rojizos-en el labio de los vasos (Fig. 4, 5-7); o en algunas copas (Fig. 6, 16-18). 
Decoraciones de este tipo son características en la cerámica protohistórica andaluza principalmente desde el siglo VII a.C. (Belén y Pereira 1985), extendiéndose su uso, con las lógicas alteraciones y evoluciones formales, estilísticas y compositivas, prácticamente hasta época romana. En el Cerro Macareno aparecen en todos los cortes practicados (Pellicer et al. 1983: 81-82; Fernández Gómez et al. 1979: 67-70; Martín de la Cruz 1976: 15, 19, fig. 8).

\subsubsection{Procesamiento y consumo de alimentos. Otros usos}

Otra serie de vasos cerrados, de diversas morfologías, podrían haber sido utilizados como pequeños contenedores de alimentos o para el tratamiento de los mismos o de otros productos de consumo. En la categoría de ollas se pueden incluir un conjunto de vasijas de cuerpo globular, con borde corto exvasado, fabricadas en pastas poco depuradas y cocidas en atmósferas reductoras, de superficies apenas tratadas mediante alisado (Fig. 6, 1-2). Además de en el Cerro Macareno (Pellicer et al. 1983: 76-77, fig. 81, 6-9), esta forma se documenta en otros yacimientos andaluces desde al menos mediados del siglo VI a.C. (Ruiz Mata y Pérez 1995: 70, fig. 24. 16-17; Aubet et al. 1999: 181-184), presentando en ocasiones líneas incisas paralelas que marcan el hombro (Ruiz Mata 1987: 309), aunque esta particularidad no la documentamos en los ejemplares del corte C.

Otra de las formas que integran el conjunto cerámico del corte C son los "lebrillos", fuentes (Ruiz Mata 1987: 311), también llamados cazuelas (Recio 1990: 73) (Fig. 4, 5-6). Se trata de recipientes abiertos, profundos y de bocas muy anchas - con diámetros en torno a los $40 \mathrm{~cm}-$, con cuerpo de perfil troncocónico o semiesférico, de paredes gruesas, bordes diferenciados de perfiles sinuosos, exvasados, de sección triangular y labio horizontal. En los casos documentados en el corte $\mathrm{C}$, las superficies se decoran con las características bandas paralelas horizontales, de distinta anchura, pintadas en tonos rojizos. Los labios suelen estar pintados, bien en toda su extensión, bien con pinceladas alternas. Los lebrillos son comunes en el Bajo Guadalquivir, bahía de Cádiz (Ruiz Mata 1987: 311; Ruiz Mata y Pérez 1995: 70) y en la costa malagueña desde el siglo VI a.C. (Aubet et al. 1999: 169-171). En el Cerro Macareno aparecen también en el corte V/20, con idéntica cronología para los ejemplares más antiguos (Pellicer et al. 1983: 93), y en los cortes E, F y G, fechados a partir del siglo V a.C. (Fernández Gómez et al. 1979: 33-36).

Similar en dimensiones es la espuerta, de cuerpo semiesférico y borde exvasado, que presenta la característica asa vertical apoyada sobre el labio de la vasija (Fig.4,7). Aun con diferencias morfológicas considerables, este tipo de vasos es especialmente frecuente en la costa malagueña (Aubet et al. 1999: 168-169), si bien escasean en la bahía de Cádiz y en el Bajo Guadalquivir.

Dentro del grupo de las vasijas destinadas al servicio de mesa, al consumo directo de los alimentos, se incluyen una parte importante del total de las cerámicas recuperadas (Gráf. 2), que comprenden platos y cuencos, pintados, sin decoración y en cerámica gris orientalizante, y algunos ejemplares de platos recubiertos de engobe rojo y copas.

La forma más numerosa la constituyen los cuencos, especialmente aquellos fabricados en pastas claras o anaranjadas, sin tratamiento decorativo alguno. Predominan los de borde engrosado al interior y aquellos de bordes simples, apenas ligeramente apuntados (Fig. 6,3-5). Esta forma en sus múltiples variantes -definidas, en todo caso, a partir de las alteraciones morfológicas de los bordes-está ampliamente extendida en todos los yacimientos protohistóricos del mediodía peninsular, manteniéndose con pocas modificaciones hasta época romana (Ruiz Mata 1987: 306). La misma forma, fabricada en pastas claras, suele decorarse frecuentemente con pintura, casi siempre de tonos rojos, en toda su superficie interior $y$, en ocasiones, al exterior, cubriendo únicamente una banda más o menos estrecha junto a la zona próxima al borde (Fig. 6, 6-7). La presencia de cuencos decorados es frecuente en numerosos yacimientos andaluces entre el siglo VI y finales del V a.C. (Ruiz Mata 1987: 306). 
También encontramos la misma forma fabricada con las características de las cerámicas grises orientalizantes -superficies bruñidas al interior y al exterior, tonos grisáceos, fruto de la cocción en atmósferas reductoras a la que son sometidas-, de las que, de hecho, constituye una de los tipos más usuales desde el siglo VII y, sobre todo, durante el VI a.C. (Fig. 6, 8-10) (Belén 1976; Caro 1989; Mancebo 1994; Vallejo 1998; Aubet et al. 1999: 158-160). De la misma cronología es la otra forma documentada de cerámica gris, la de plato o cuenco de borde exvasado, diferenciado éste del cuerpo semiesférico por una carena o por una simple inflexión de la pared (Fig. 6, 11-12).

Estas formas -el cuenco, con todas sus variaciones morfológicas y técnicas, y el plato o cuenco en cerámica gris orientalizante-aparecen con gran profusión en todo el mediodía peninsular, prácticamente en todos los yacimientos conocidos hasta la fecha.

Del corte C, procedentes de los derrumbes de los niveles superiores de la estratigrafía, contamos con un reducido número de interesantes platos recubiertos de engobe rojo (Fig. 6, 14-15). Presentan bordes exvasados, muy desarrollados, separados del cuerpo propiamente dicho por una carena al exterior y una clara inflexión al interior. El extremo del borde sobresale ofreciendo una sección de tendencia triangular, a modo de ala. El fondo está indicado, anunciando a veces un pie incipiente, y la base suele presentar un ónfalo. En los ejemplares del corte $\mathrm{C}$ podemos apreciar la característica tendencia a prolongar los bordes propia de los platos turdetanos, a partir de sus antecedentes formales, los platos de engobe rojo arcaicos (Ruiz Mata 1987: 304). Este alargamiento origina en el fondo del vaso un pocillo que, junto a los bordes prolongados y los labios en pestaña, serán características que encontraremos en la vajilla posterior (Niveau de Villedary 2000: $182 \mathrm{ss}$.). Estos platos están presentes principalmente durante el siglo V a.C. -sobre todo, en su segunda mitad- en yacimientos como el Castillo de Doña Blanca (Ruiz Mata 1987: 304; Ruiz Mata y Pérez Pérez 1995: 69, 73, fig. 26, 3-5) o el propio Cerro Macareno (Pellicer et al. 1983: 93-94, fig. 103: 4-6). Junto a estos platos, y con una cronología del siglo IV a.C., contamos con un cuenco de pequeño tamaño $-10 \mathrm{~cm}$ de diámetro-, también recubierto de engobe rojo, de cuerpo semiesférico, borde de tendencia vertical, señalado por una inflexión en la pared, y labio ligeramente apuntado (Fig. 6, 13). La misma forma se documentó también en el corte V/20, en los niveles del siglo IV a.C. (Pellicer et al. 1983: fig. 101, 27).

Formando también parte de la vajilla de mesa encontramos pequeños vasos de perfil en $\mathrm{S}$, de bordes ligeramente exvasados, diferenciados en algunos casos por una suave carena que los separa del cuerpo semiesférico (Fig. 6, 16-18). Las superficies, alisadas, están decoradas con bandas pintadas de color rojovinoso, señalando el borde al exterior, hasta la carena o inflexión de la pared, y también al interior, con otra banda, más estrecha, junto al mismo labio. Esta forma está documentada en otros yacimientos del Bajo Guadalquivir en la primera mitad del siglo VI a.C. (Ruiz Mata y Pérez Pérez 1995: 70) y podría imitar a prototipos jonios, documentados en el sur de la Península a finales del siglo VII a.C. (Ruiz Mata 1995 a: 185; Aubet et al. 1999: 138; Cabrera 1994: 103-105).

\section{EL CONTEXTO: EL SIGLO VI a.C.}

A lo largo del siglo VI a.C. se producen en el sur de la Península Ibérica una serie de cambios de diversa índole que desembocan en una nueva realidad socio-económica y política que la historiografía científica denominó en su momento "crisis del siglo VI a.C.". Tradicionalmente se consideró que estas, en apariencia, profundas alteraciones estaban motivadas por la caída de la principal metrópoli fenicia, Tiro, en manos del monarca asirio Nabuconodosor, en el 573 a.C. (López Castro 1996). Este hecho provocó en Occidente, siempre desde este punto de vista, una grave e irreversible crisis en la producción de la plata (Alvar 1991: 25; Fernández Jurado 1995: 415-416; Ruiz Mata 1989: 239) asociada, según otros investigadores, a la pérdida 
del control del comercio del estaño por parte de Gadir (González Wagner 1983: 234-237) o a una severa crisis agrícola (Belén y Escacena 1992). Los cambios que a nivel general se producen en el Mediterráneo, con la entrada en juego de diversos Estados de creciente protagonismo (Plácido, Alvar y González Wagner 1991) afectan a la Península Ibérica que, una vez alterada seriamente la posición de Gadir en las relaciones internacionales -siempre según la visión más tradicional-, entra a formar parte en la trama de intereses de esas fuerzas en puja constante (De Frutos 1991). No cabe duda, a la luz de las investigaciones de la última década, que esta visión tradicional ha abusado del hecho de la "caída" de la ciudad fenicia, que no destrucción, así como ha infravalorado la propia autonomía de las colonias occidentales y el carácter de sus relaciones con las economías y sociedades autóctonas (Alvar 1991; Alvar, Martínez Maza y Romero 1992). Actualmente se matiza el control de Cartago en el occidente mediterráneo, bien fuese éste de carácter político, bien de carácter económico. Se resalta, especialmente la autonomía de la zona de Gadir en los aspectos políticos (Arteaga 1994) y económicos (Ruiz Mata 1997). Desde estos nuevos modos de aproximación al problema, la "crisis del siglo VI a.C." aparece como una reconversión de las estructuras existentes a unas nuevas circunstancias políticas, económicas y sociales. Las estrategias económicas practicadas hasta entonces, basadas en un modelo de explotación colonial y en la extracción y comercialización de metales (Aubet 1994), son sustituidas por otras fundadas en el incremento de la explotación e industrialización de productos agropecuarios y pesqueros, orientados a nuevos mercados del Mediterráneo Central y norteafricanos, que reemplazarán a los orientales (Ruiz Mata 1997; 1998; Ruiz Mata et al. 1998; Delgado et al. 2000). En consonancia con estos cambios, asistimos a un reordenamiento del territorio, apreciándose un abandono o declive de aquellos enclaves directamente relacionados con la explotación minero-metalúrgica (Fernández Jurado 1987 b) y un crecimiento y potenciación de aquellos asentamientos que contaban con una importante base agropecuaria, que jalonan las fértiles tierras del valle del Guadalquivir, los bordes de marismas, esteros y campiñas (Murillo 1994: 472-473; Belén y Escacena 1992: 72). En relación a estos grandes núcleos urbanos, aparecen pequeños enclaves rurales vinculados a la explotación de los recursos agropecuarios y a su posterior transformación industrial (Ruiz Mata et al. 1998).

Toda esta nueva situación que empieza a tomar forma durante el siglo VI a.C. y que irá consolidándose en los siglos sucesivos constituye una nueva realidad, profundamente enraizada en las etapas anteriores, que denominamos mundo turdetano ${ }^{4}$. El nexo con el período orientalizante nos parece innegable, como podemos rastrear por numerosos indicios que la Arqueología nos proporciona (Ruiz Mata et al. 1998). El estudio de la cultura material y, dentro de ella, el de la cerámica, supone una herramienta imprescindible y de gran ayuda a la hora de valorar los elementos de continuidad y cambio en estas facetas de la sociedad, que, de algún modo, remiten a otros acaecidos en diferentes esferas. Centrándonos en el caso particular que nos ocupa, mediante este análisis creemos que es posible apreciar algunas de estos procesos de alteraciones, novedades y perduraciones.

La presencia de cerámica a mano durante el siglo VI a.C. -y aún en épocas posteriores si observamos sus comportamientos en el mismo Cerro Macareno (Pellicer et al. 1983: 63 ss.)-es uno de los elementos que nos informa sobre la continuidad respecto al pasado inmediato. Estas cerámicas continúan una tradición que se remonta al Bronce Final, como hemos podido ver en el análisis detenido de las distintas formas, así como en la tecnología empleada para su fabricación y los usos a los que son destinadas. A medida que avanzamos en el tiempo, comprobamos como el número de estas vasijas disminuye en una relación inversamente proporcional respecto al porcentaje de cerámicas fabricadas a torno (Gráfs. 1-2). Este fenómeno se constata

4. No entraremos a discutir aquí los problemas terminológicos y conceptuales que encierra esta denominación, pues excederíamos los objetivos planteados en el presente artículo. Remitimos para ello a otros trabajos en los que abordamos esta cuestión con detenimiento: Ruiz Mata 1997 y 1998; Ferrer 1996 y 1998. 
en la práctica totalidad de los yacimientos conocidos para este período, tanto en la zona onubense (FernándezJurado 1988-1989), como en el Bajo Guadalquivir (Pellicer et al. 1983: figs. 77, 80) o en la Bahía de Cádiz (Ruiz Mata y González Rodríguez 1994: figs. 24, 25). Si observamos las formas presentes en el Cerro Macareno -a partir del corte V/20, en este caso- apreciamos como la mayoría de ellas se concentran en los estratos datados en los siglos VIII y VII a.C., siendo minoritaria su presencia en los niveles del siglo VI y posteriores. Muchas de estas formas empezarán a ser sustituidas a partir de estos momentos por otras realizadas a torno que cumplirán una función análoga. Evidencia clara de esto y de la continuịdad, no sólo en las formas sino también en el propio aspecto global de las piezas, lo constituyen las cerámicas grises orientalizantes. Éstas, consideradas en su conjunto, tienen su más claro referente en la tradición de las cerámicas realizadas a mano del Bronce Final (Vallejo 1998; 2000; e.p.).

Relaciones de este tipo encontramos también en otras formas cerámicas, como las ollas. La pervivencia de los modelos realizados a mano -basados en prototipos de los siglos VIII y VII a.C.- aún en períodos de claro predominio de las cerámicas torneadas, como es el caso del siglo VI a.C. (Gráfs. 1-2), subrayan estas continuidades a las que venimos refiriéndonos. No será hasta entrado el siglo VI a.C. cuando estas ollas empiecen a ser sustituidas por sus análogas hechas a torno, sin que ello implique su desaparición inmediata.

El siglo VII a.C. supone el punto de partida de muchas de las formas que luego compondrán la vajilla típica del siglo VI a.C. Así sucede con los vasos contenedores hallados en el corte C (Fig. 5) tan comunes en otros yacimientos del sur peninsular, cuyos más remotos prototipos se remontan incluso al siglo VIII a.C. Tampoco podemos afirmar una solución de continuidad entre los materiales anfóricos del siglo VII y VI a.C. Las formas y los tipos, como en los casos anteriores, se adaptan y se van transformando, pero el referente de las vasijas preexistentes no deja de percibirse. La evolución de los típicos platos de engobe rojo sigue también unas pautas perceptibles desde el siglo VII a.C., al menos, que desembocarán en las formas características de la vajilla turdetana de los siglos VI y siguientes (Ruiz Mata 1987: 304).

Además de las variaciones tipológicas de las formas previas, se hacen evidentes también a partir de este momento una serie de novedades, como la aparición de los lebrillos, tan comunes desde entonces, y las copas pintadas de inspiración jonia (Fig. 6, 16-18), dentro éstas del contexto de la llegada de materiales procedentes de la Grecia del Este, constatable desde finales del siglo VII a.C. (Shefton 1982; Cabrera 1995; Id. 1997; Niveau de Villedary y Vallejo Sánchez 2001). Aunque tradicionalmente este hecho se ha interpretado como el resultado del nuevo orden del comercio mediterráneo establecido después del enfrentamiento entre los bloques antagónicos griegos versus fenicios (Domínguez Monedero 1991), actualmente se considera reflejo de las nuevas orientaciones de los mercados occidentales en el Mediterráneo y de la propia situación de las ciudades jonias durante aquellos años (Cabrera 1995; Domínguez Monedero 1996: 32-33).

Si tomamos como referencia y punto de partida para este análisis los objetos recuperados en las excavaciones del corte $\mathrm{C}$ del Cerro Macareno, vemos cómo son numerosos los ejemplos de continuidad en la cultura material cerámica de este momento. La escisión que suponía la interpretación clásica de la crisis del siglo VI a.C. no encuentra confirmación a la luz de los datos materiales, lo que viene a sumarse a otras evidencias que el avance de la investigación pone cada vez más de relieve. Es innegable, sin embargo, el hecho de que se producen cambios importantes en el sur peninsular, por lo que es necesario continuar indagando para establecer el verdadero alcance de estas alteraciones y definir el proceso del que formaron parte. 


\section{BIBLIOGRAFÍA}

ALVAR, J. (1991): "La caída de Tiro y sus repercusiones en el Mediterráneo", La caída de Tiro y el auge de Cartago. V Jornadas de Arqueología Fenicio-Púnica de Ibiza (Ibiza, 1990): 19-27. Ibiza.

— ; MARTÍNEZ MAZA, C. y ROMERO, M. (1992): "La (supuesta) participación de Cartago en el fin de Tartesso", Habis 23: 39-52.

AMBERGER, G. (1985): "Tierknochenfunde vom Cerro Macareno/Sevilla", Studien über frühe Tierknochenfunde von der Iberischen Halbinsel 9: 76-105.

ARTEAGA MATUTE, O. (1994): "La liga púnico-gaditana. Aproximación a una visión histórica occidental, para su contrastación con el desarrollo de la hegemonía cartaginesa en el mundo mediterráneo", Cartago, Gadir, Ebusus y la influencia púnica en los territorios hispanos. VIII Jornadas de Arqueología feniciopúnica de Ibiza (Ibiza, 1993): 23-57. Ibiza.

AUBET SEMMLER, Ma . E. (1978): La Necrópolis de Setefilla en Lora del Río, Sevilla (Túmulo B). Barcelona, C.S.I.C.-Universidad de Barcelona.

(1994): Tiro y las colonias fenicias de Occidente (Edición ampliada y puesta al día). Barcelona, Grijalbo. ; CARMONA, P.; CURIÀ, E.; DELGADO, A.; FERNÁNDEZCANTOS, A. y PÁRRAGA, M. (1999): Cerro del Villar - I. El asentamiento fenicio en la desembocadura del río Guadalhorce y su interacción con el hinterland. Sevilla, Junta de Andalucía .

BELÉN DEAMÓS, Ma . (1976): "Estudio y tipología de la cerámica gris de Huelva", Revista de Archivos, Bibliotecas y Museos LXXIX(2): 353-388.

- y ESCACENA CARRASCO, J.L. (1992): "Las comunidades prerromanas de Andalucía Occidental”, Complutum 2-3: 65-87.

— y PEREIRA SIESO, J. (1985): “Cerámicas a torno con decoración pintada en Andalucía”, Huelva Arqueológica VII: 307-360.

BLÁZQUEZ, J. Mª; RUIZ MATA, D.; REMESAL, J.; RAMÍREZ, J.L. y CLAUSS, K. (1979): Excavaciones en el Cabezo de San Pedro (Huelva). Campaña de 1977. Madrid.

CABRERA BONET, P. (1994): "Importaciones griegas arcaicas del Cerro del Villar (Guadalhorce, Málaga)", Iberos y griegos: lecturas desde la diversidad. Simposio Internacional celebrado en Ampurias, 3 al 5 de abril de 1991. Huelva Arqueológica XIII: 97-125.

(1995): "Cerámicas griegas en Tartesos: su significado en la costa meridional de la Península desde Málaga a Huelva", Tartessos 25 años después (1968-1993). Actas del Congreso Conmemorativo del V Symposium Internacional de Prehistoria Peninsular (Jerez, 1993): 387-399. Jerez de la Frontera.

- (1997): "La presencia griega eñ Andalucía (siglos VI al IV a.C.)", La Andalucía Ibero-turdetana (siglos VI-IV a.C.) (Huelva, 1994). Huelva Arqueológica XIV: 367-390.

CARO BELLIDO, A. (1989): Cerámica gris a torno tartesia. Cádiz, Universidad de Cádiz.

CHIC, G. y DE FRUTOS, G. (1984): "La Península Ibérica en el marco de las colonizaciones mediterráneas", Habis 15: 201-227.

CÓRDOBA ALONSO, I. y RUIZ MATA, D. (2000): "Sobre la construcción de la estructura tumular del Túmulo 1 de Las Cumbres (Castillo de Doña Blanca)", Actas del IV Congreso Internacional de Estudios Fenicios y Púnicos II: 759-770. Cádiz.

DELGADO HERVÁS, A.; FERNÁNDEZ CANTOS, A. y RUIZ MARTÍNEZ, A. (2000): "Las transformaciones del s. VI a.n.e. en Andalucía: una visión de las relaciones entre fenicios e indígenas", Actas del IV Congreso Internacional de Estudios Fenicios y Púnicos (Cádiz, 1995) IV: 1781-1787. Cádiz. 
DOMÍNGUEZ MONEDERO, A.J. (1991): "El enfrentamiento etrusco-foceo en Alalia y su repercusión en el comercio con la Península Ibérica”, J. Remesal y O. Musso (Coords.), La presencia de material etrusco en la Península Ibérica: 239-273. Barcelona.

- (1996): Los griegos en la Península Ibérica. Madrid, Arco.

ESCACENA CARRASCO, J. L. (2000): La Arqueología Protohistórica del sur de la Península Ibérica. Madrid, Ed. Síntesis.

FERNÁNDEZ CHICARRO, C. (1974): “Adquisiciones del Museo Arqueológico de Sevilla”, Bellas Artes 74 33: 31.

FERNÁNDEZ GÓMEZ, F.; CHASCO VILA, R. y OLIVA ALONSO, D. (1979): "Excavaciones en el Cerro Macareno (cortes E, F, G. Campañas 1974)", Noticiario Arqueológico Hispánico 7: 7-93.

FERNÁNDEZ-JURADO, J. (1987 a): Tejada la Vieja. Una ciudad protohistórica. Huelva.

- (1987 b): "El poblamiento ibérico en Huelva", Iberos. Actas de las I Jornadas sobre el Mundo Ibérico (Jaén, 1985): 315-326. Jaén.

- (1988-89): Tartessos y Huelva. Huelva.

- (1995): "Economía metalúrgica de Tartessos", Tartessos 25 años después (1968-1993). Actas del Congreso Conmemorativo del V Symposium Internacional de Prehistoria Peninsular (Jerez, 1993): 411-416. Jerez de la Frontera.

FERRER ALBELDA, E. (1996): “Los púnicos de Iberia y la historiografía grecolatina”, Spal 5: 115-131.

_ (1998): "Suplemento al mapa paleoetnológico de la Península Ibérica: los púnicos de Iberia", Rivista di Studi Fenici XXVI, 1: 31-54.

FLORIDO NAVARRO, C. (1984): “Ánforas prerromanas sudibéricas”, Habis 15: 419-436.

GÓMEZ TOSCANO, F. (1997): El final de la Edad del Bronce entre el Guadiana y el Guadalquivir. El territorio y su ocupación. Huelva, Universidad de Huelva.

GONZÁLEZ VÍlCHEZ, C.; GARCÍA RAMOS, G. y GONZÁLEZ GARCÍA, F. (1985): "Productos de alfarería de Cerro Macareno (Sevilla). Naturaleza y procedencia de las ánforas y otros objetos cerámicos. Siglos VIII al III a.J.C.”, Noticiario Arqueológico Hispánico 21: 157-174.

LADRÓN DE GUEVARA SÁNCHEZ, I. (1994): Aportación al estudio de la cerámica con impresiones digitales en Andalucía. Cádiz, Universidad de Cádiz.

LÓPEZ CASTRO, J. L. (1994): "Cartago y la Península Ibérica en la Historiografía española reciente (1980-1992)", Hispania Antiqua XVIII: 519-532.

- (1996): "Fenicios y cartagineses en la obra de Adolf Schulten: una aproximación historiográfica", Gerión 14: 289-331.

LÓPEZ ROA, C. (1977): “Las cerámicas con decoración bruñida en el suroeste peninsular”, Trabajos de Prehistoria 34: 341-370.

- (1978): "Las cerámicas alisadas con decoración bruñida", Huelva Arqueológica IV: 145-180.

MANCEBO DÁVALOS, J. (1994): "Las cerámicas grises a torno orientalizantes de la cuenca baja del Guadalquivir", Arqueología en el entorno del Bajo Guadiana. Actas del Encuentro Internacional de Arqueología del Suroeste (Huelva, Nieba, 1993): 351-373. Huelva.

MARTÍN DE LA CRUZ, J. C. (1975): El corte F del Cerro Macareno. Un yacimiento del Bajo Guadalquivir. Memoria de Licenciatura, Universidad de Sevilla.

- (1976): "El corte F del Cerro Macareno, La Rinconada (Sevilla)", Cuadernos de Prehistoria y Arqueología de la Universidad Autónoma de Madrid 3: 9-31.

MARTÍN RUIZ, J. M. (2000): "Cerámicas a mano en los yacimientos fenicios de Andalucía", Actas del IV Congreso Internacional de Estudios Fenicios y Púnicos (Cádiz, 1995) IV: 1625-1630. Cádiz. 
MURILLO REDONDO, J. F. (1994): La cultura tartésica en el Guadalquivir Medio, Ariadna 13-14. NIVEAU DE VILLEDARY Y MARIÑAS, A. Mª . (2000): "La producción de cerámicas rojas de tradición griega en la zona de Cádiz", Madrider Mitteilungen 41: 178-196.

— y VALLEJO SÁNCHEZ, J. I. (2001): "Evolución y estructura del comercio gaditano en época púnica. Un avance a partir de la documentación arqueológica, I. (ss. VI-IV a.n.e.)", I Coloquio del Centro de Estudios Fenicios y Púnicos. "Intercambio y comercio precñásico en el Mediterráneo" (Madrid 1998): 317-341. Madrid.

PELLICER CATALÁN, M. (1976-1978): "Problemática general de los inicios de la iberización en Andalucía occidental”, Simposi Internacional: Els Orígens del Món Ibèric (Barcelona-Empúries, 1977): 3-21. Barcelona.

(1978): "Tipología y cronología de las ánforas prerromanas del Guadalquivir, según el Cerro Macareno (Sevilla)", Habis IX: 365-400.

- (1979): "El tránsito del Bronce Final al Hierro en el Cerro Macareno, Sevilla", I Mesa Redonda sobre a pré e a protohistória do Sudoeste Peninsular, Setúbal (Portugal).

—_ (1980): "Ensayo de periodización y cronología tartesia y turdetana", Habis 10: 307-333.

(1982): "Las cerámicas del mundo fenicio en el Bajo Guadalquivir. Evolución y cronología según el Cerro Macareno (Sevilla)", Phönizier im Westen. Symposium "Die phönizische Expansion im westlinchen Mittelmeerraum" (Köln, 1979): 371-406. Mainz am Rheim.

_-(1995): "Balance de 25 años de investigación sobre Tartessos (1968-1993)", Tartessos 25 años después (1968-1993). Actas del Congreso Conmemorativo del V Symposium Internacional de Prehistoria Peninsular (Jerez, 1993): 41-71. Jerez de la Frontera.

— y BENDALA GALÁN, M. (1977): "La estratigrafía del Cerro Macareno y su contribución a la cronología de la protohistoria tartésica", VIII Symposium Internacional de Prehistoria Peninsular (Córdoba, 1976). Córdoba (Inédito).

PELLICER CATALÁN, M.; ESCACENA CARRASCO, J.L. y BENDALA GALÁN, M. (1983): El Cerro Macareno. Madrid.

RAMÓN TORRES, J. (1995): Las ánforas fenicio-púnicas del Mediterráneo Central y Occidental. Barcelona. RECIO, A. (1990): La cerámica fenicio-púnica, griega y etrusca del sondeo de San Agustín (Málaga). Málaga.

RUIZ MATA, D. (1981): "El poblado metalúrgico de época tartésica de San Bartolomé(Almonte, Huelva)." Madrider Mitteilungen 22: 150-170.

- (1987): "La formación de la cultura turdetana en la Bahía de Cádiz a través del Castillo de Doña Blanca", Iberos. Actas de las I Jornadas sobre el Mundo Ibérico (Jaén, 1985): 299-314. Jaén.

- (1989): "Huelva: un foco temprano de actividad metalúrgica durante el Bronce Final", Tartessos. Arqueología Protohistórica del Bajo Guadalquivir: 209-243. Sabadell, Ausa.

- (1995 a): "El vino en época prerromana en Andalucía occidental", Arqueología del vino. Los orígenes del vino en Occidente: 157-212. Jerez de la Frontera.

- (1995 b): "Las cerámicas del Bronce Final. Un soporte tipológico para delimitar el tiempo y el espacio tartésico", Tartessos 25 años después (1968-1993). Actas del Congreso Conmemorativo del V Symposium Internacional de Prehistoria Peninsular (Jerez, 1993): 265-313. Jerez de la Frontera.

- (1997): "Fenicios, tartesios y turdetanos", La Andalucía Ibero-turdetana (siglos VI-IV a.C.)(Huelva, 1994). Huelva Arqueológica XIV: 325-365.

- (1998): "Turdetanos: origen, territorio y delimitación del tiempo histórico", Revista de Estudios Ibéricos 3: 153-221. 
; BLÁZQUEZ, J.Ma . y MARTÍN DE LA CRUZ, J.C. (1981): "Excavaciones en el Cabezo de San Pedro (Huelva). Campaña de 1978", Huelva Arqueológica V: 149-316.

y CÓRDOBA ALONSO, I. (1999): "Los hornos turdetanos del Cerro Macareno. Cortes H.I y H.II", XXIV Congreso Nacional de Arqueología (Cartagena, 1997). 3: Impacto colonial y Sureste Ibérico: 95-105. Murcia.

; CÓRDOBA ALONSO, I. y PÉREZ PÉREZ, C.J. (1998): “Vinos, aceites y salazones en la Turdetania”, Actas del Congreso Internacional "Los Iberos Príncipes de Occidente: Estructuras de poder en la sociedad ibérica" (Barcelona, 1998): 387-397. Barcelona.

— y FERNÁNDEZ-JURADO, J. (1986): El yacimiento metalúrgico de época tartésica de San Bartolomé (Almonte, Huelva). Huelva.

—— y GONZÁLEZ RODRÍGUEZ, R. (1994): "Consideraciones sobre asentamientos rurales y cerámicas orientalizantes en la campiña gaditana", Spal 3: 209-256.

; NIVEAU DE VILLEDARY Y MARIÑAS, A.Ma . y VALLEJO SÁNCHEZ, J.I. (1998): "La ciudad tartésico-turdetana", Actas del Congreso Internacional "Los Iberos Príncipes de Occidente: Estructuras de poder en la sociedad ibérica" (Barcelona, 1998): 65-82. Barcelona.

—y PÉREZ PÉREZ, C.J.(1989): "El túmulo 1 de la necrópolis de "Las Cumbres"”, Tartessos. Arqueología Protohistórica del Bajo Guadalquivir: 287-295. Sabadell, Ausa.

SHEFTON, B.B. (1982): "Greeks and greek imports in the south of the Iberian Peninsula. The archaoelogical evidence", Phönizier im Westen. Symposium "Die phönizische Expansion im westlinchen Mittelmeerraum" (Köln, 1979): 337-368. Mainz am Rheim.

TORRES ORTIZ, M. (1996): "La cronología de los túmulos A y B de Setefilla. El origen del rito de cremación en la cultura tartésica", Complutum 7: 147-162.

VALLEJO SÁNCHEZ, J. I. (1998): "Sobre el origen y extensión de la cerámica gris y las producciones occidentales", Actas del I Congreso Español de Estudios del Próximo Oriente "El Mediterráneo en la Antigüedad: Oriente y Occidente" (Madrid, 1998). Madrid.

- (2000): "Las decoraciones bruñidas en las cerámicas grises orientalizantes", Spal 8 (1999): 85-100.

— (e.p.): "Fenicios e indígenas en el sur de la Península Ibérica: las cerámicas grises orientalizantes del Castillo de Doña Blanca", Atti del V Congresso Internazionale di Studi Fenici e Punici (MarsalaPalermo, ottobre de 2000).

WAGNER, C. G. (1983): Fenicios y cartagineses en la Península lbérica: Ensayo de interpretación fundamentado en un análisis de los factores internos. Tesis Doctoral reprografiada. Madrid, Universidad Complutense. 


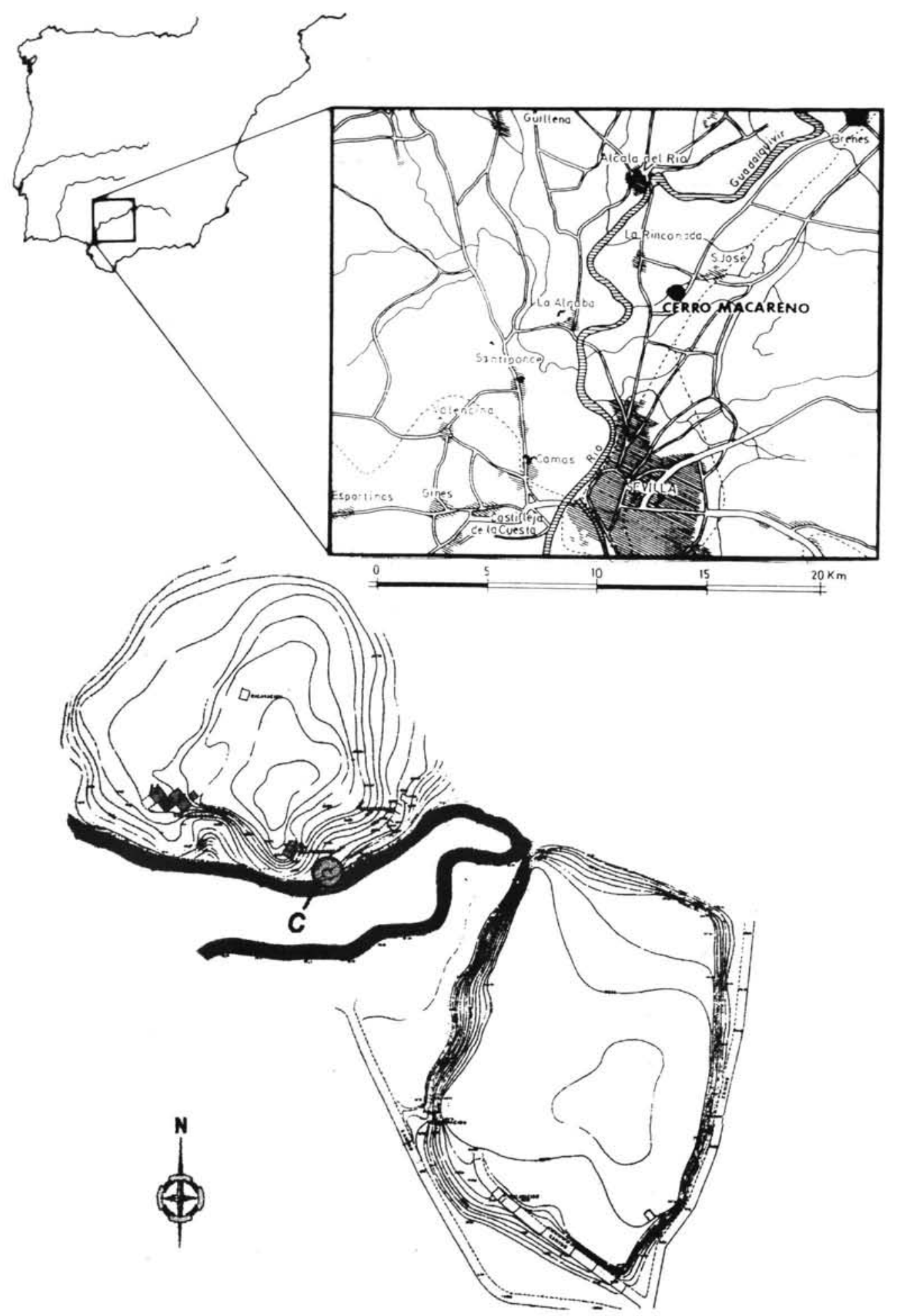

Figura 1. Localización del yacimiento del Cerro Macareno y situación del corte C (a partir de Fernández Gómez et al. 1979). 


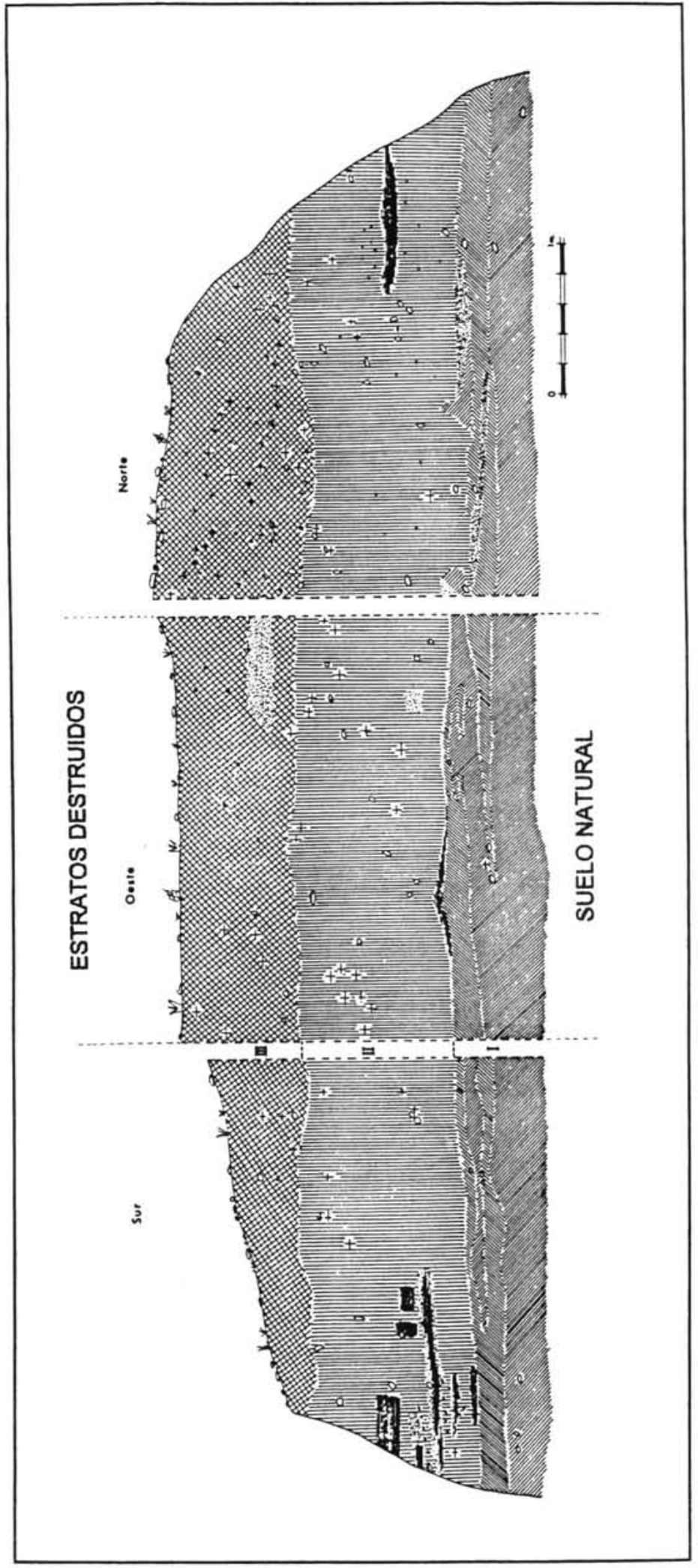

ปั. 

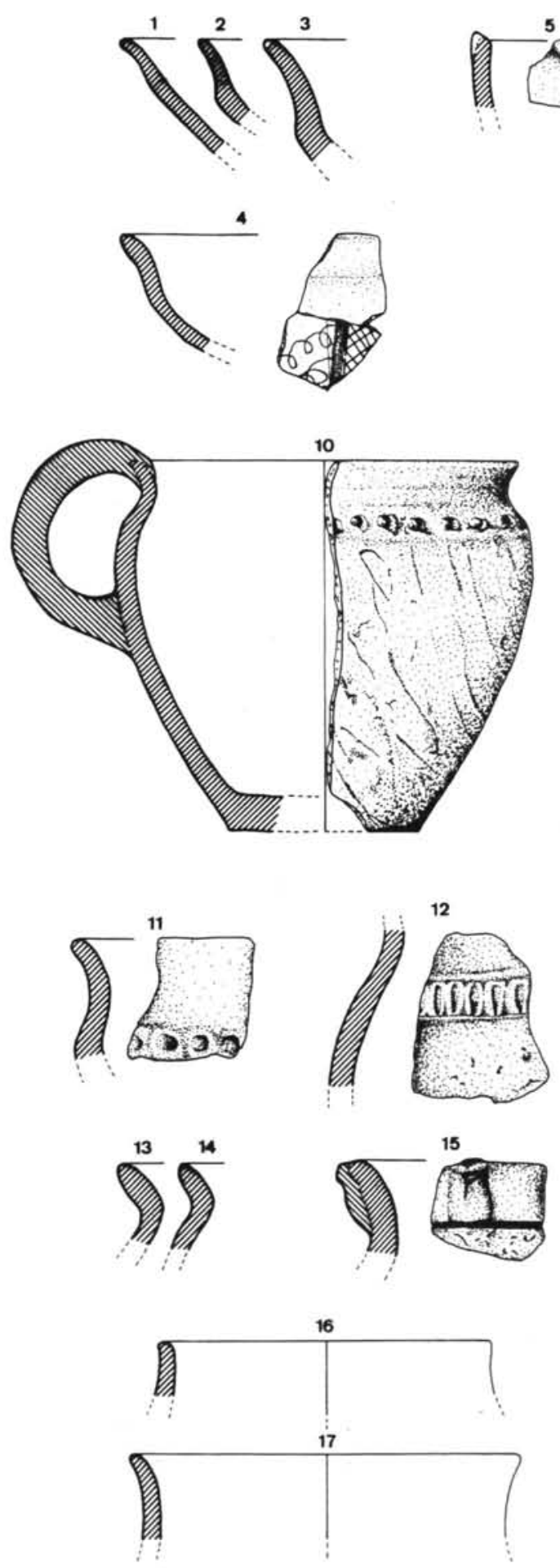
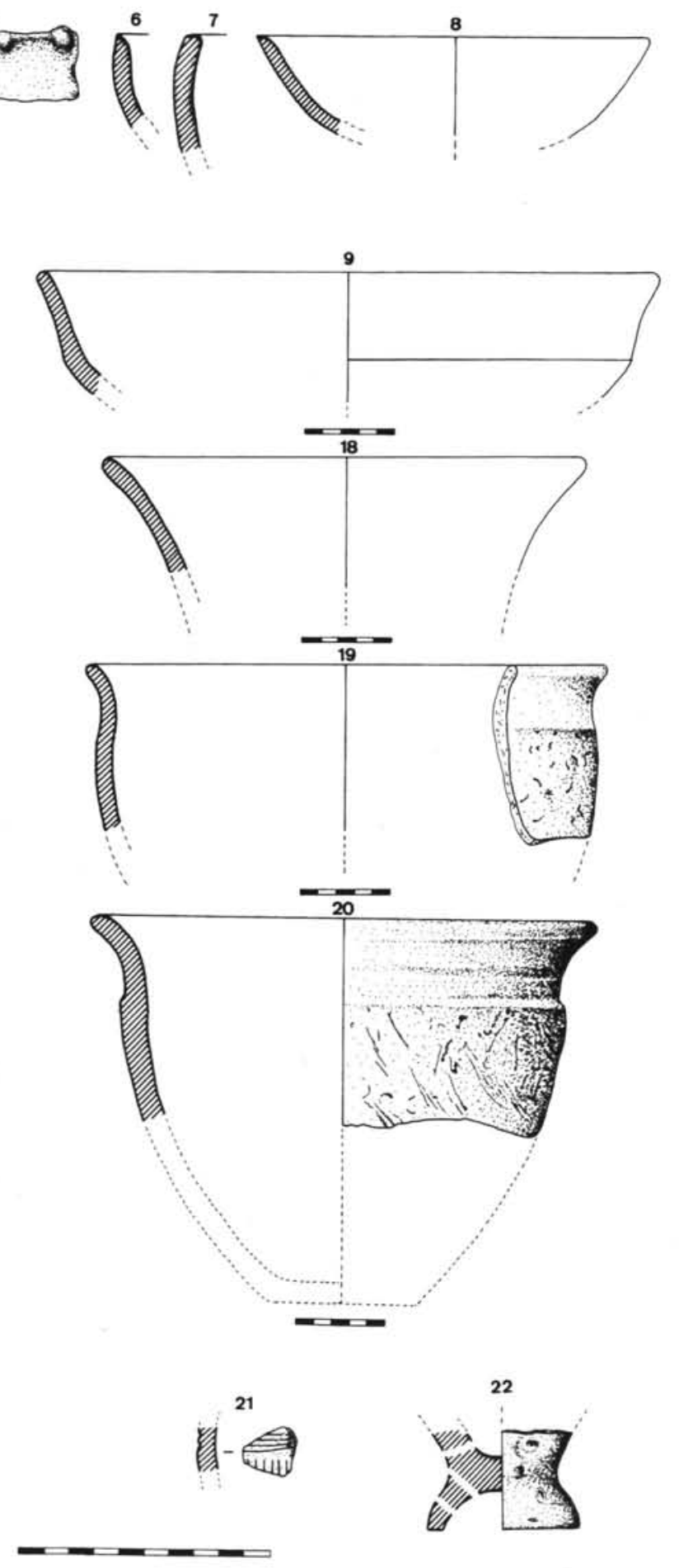

Figura 3. Cerámicas a mano del corte $\mathrm{C}$ del Cerro Macareno. 

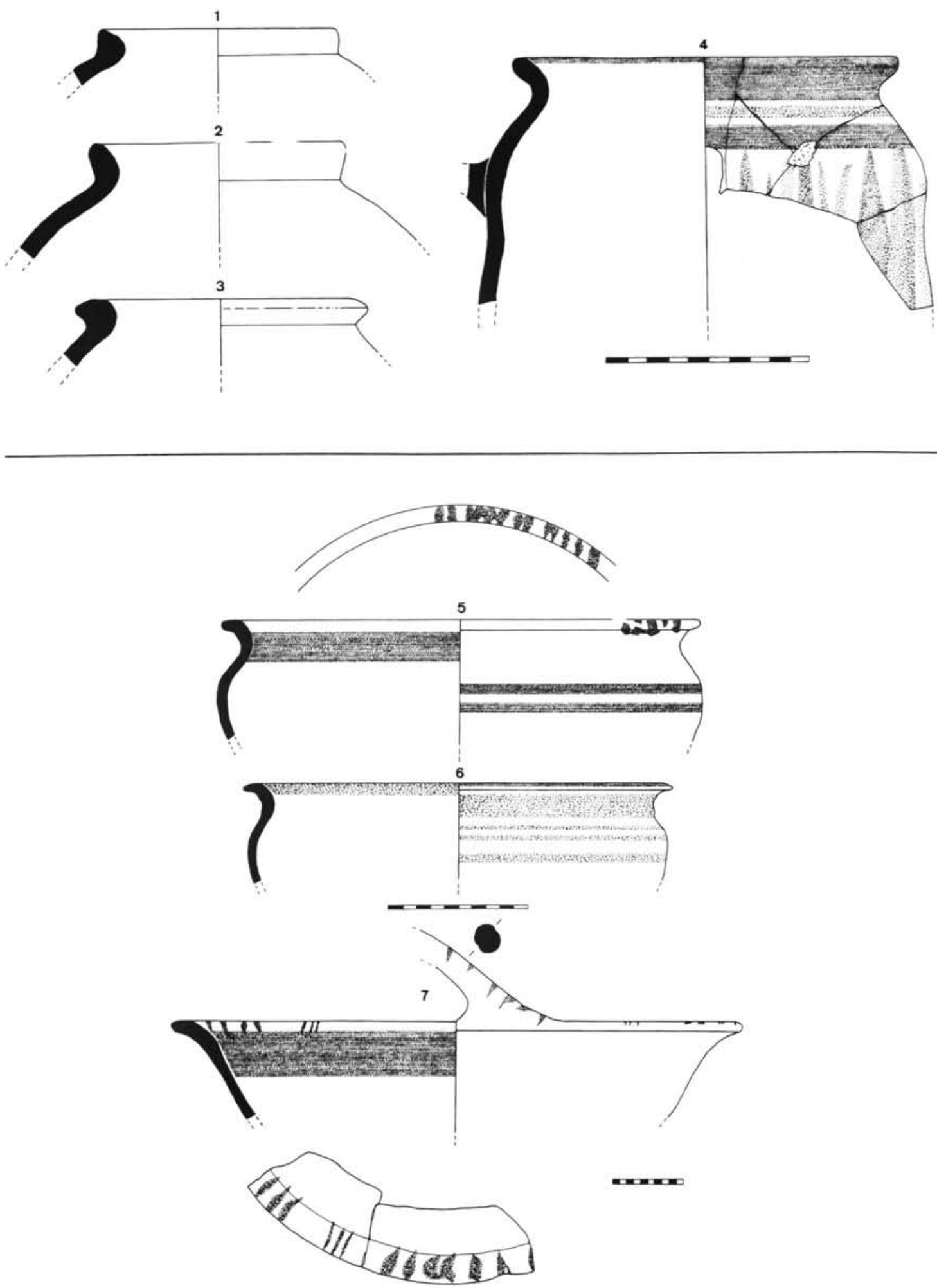

Figura 4. Cerámicas a torno del corte $\mathrm{C}$ del Cerro Macareno: ánforas, lebrillos, espuerta. 


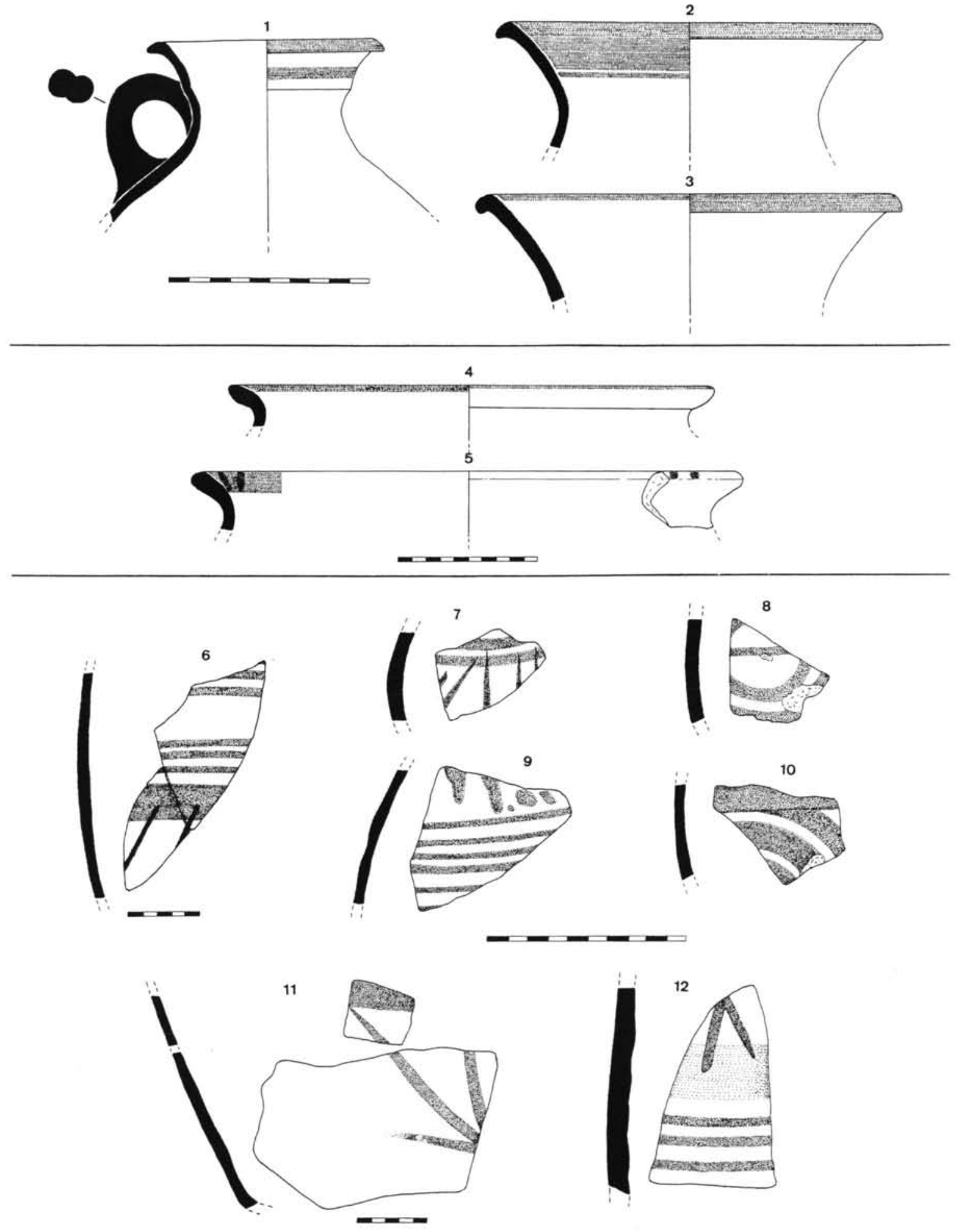

Figura 5. Cerámicas a torno del corte $\mathrm{C}$ del Cerro Macareno: vasos de almacenaje. 

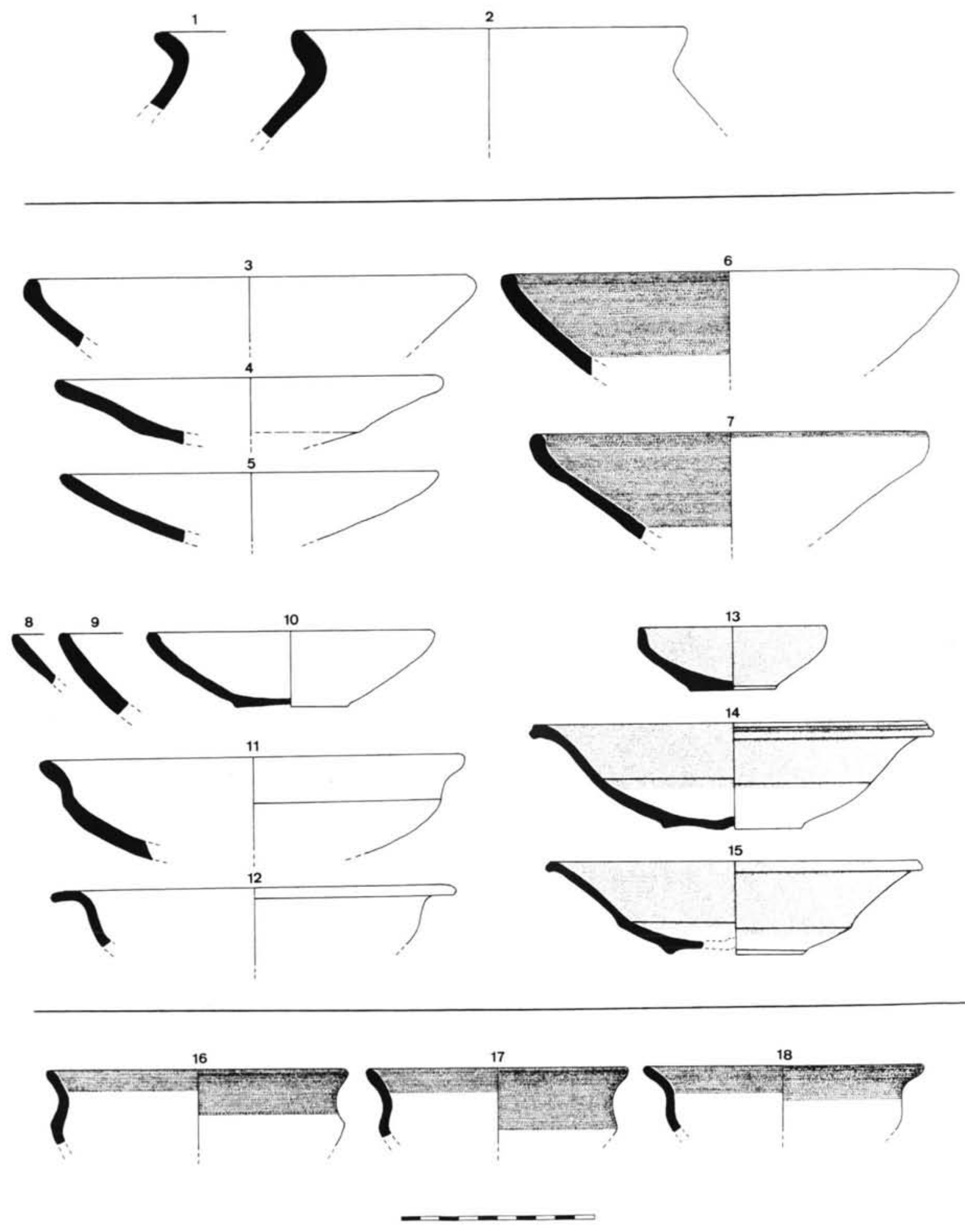

Figura 6. Cerámicas a torno del corte $\mathrm{C}$ del Cerro Macareno: ollas; servicio de mesa. 


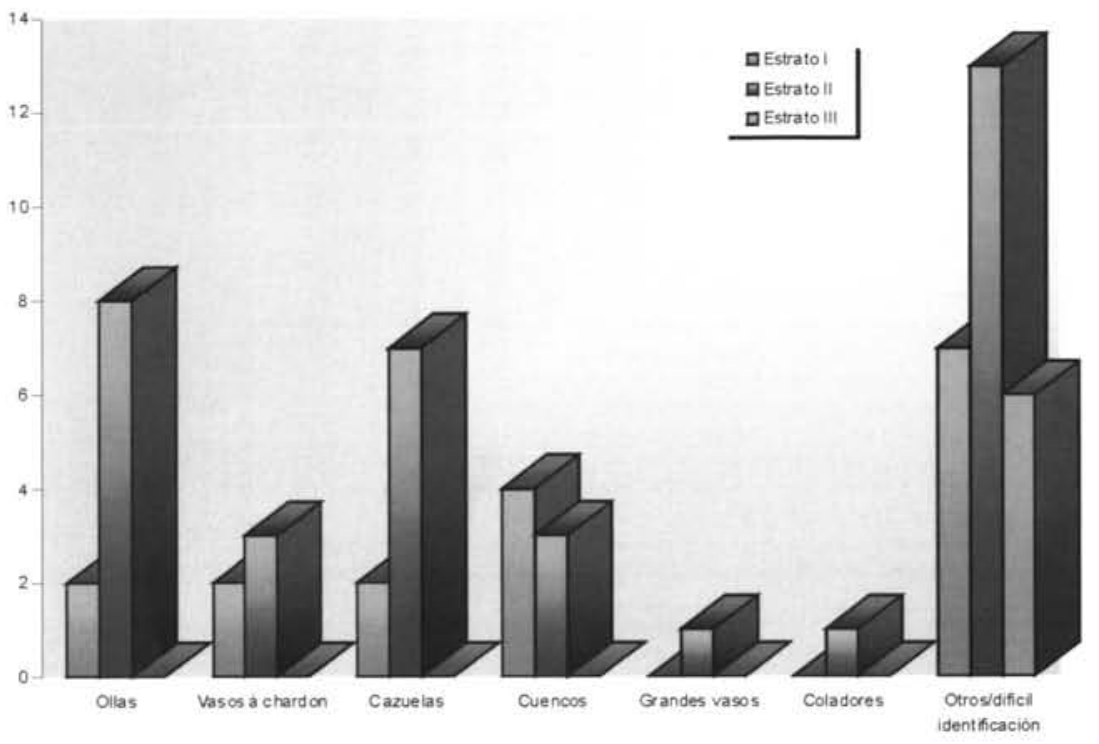

Gráfico 1. Proporciones de cerámicas a mano del corte C del Cerro Macareno.

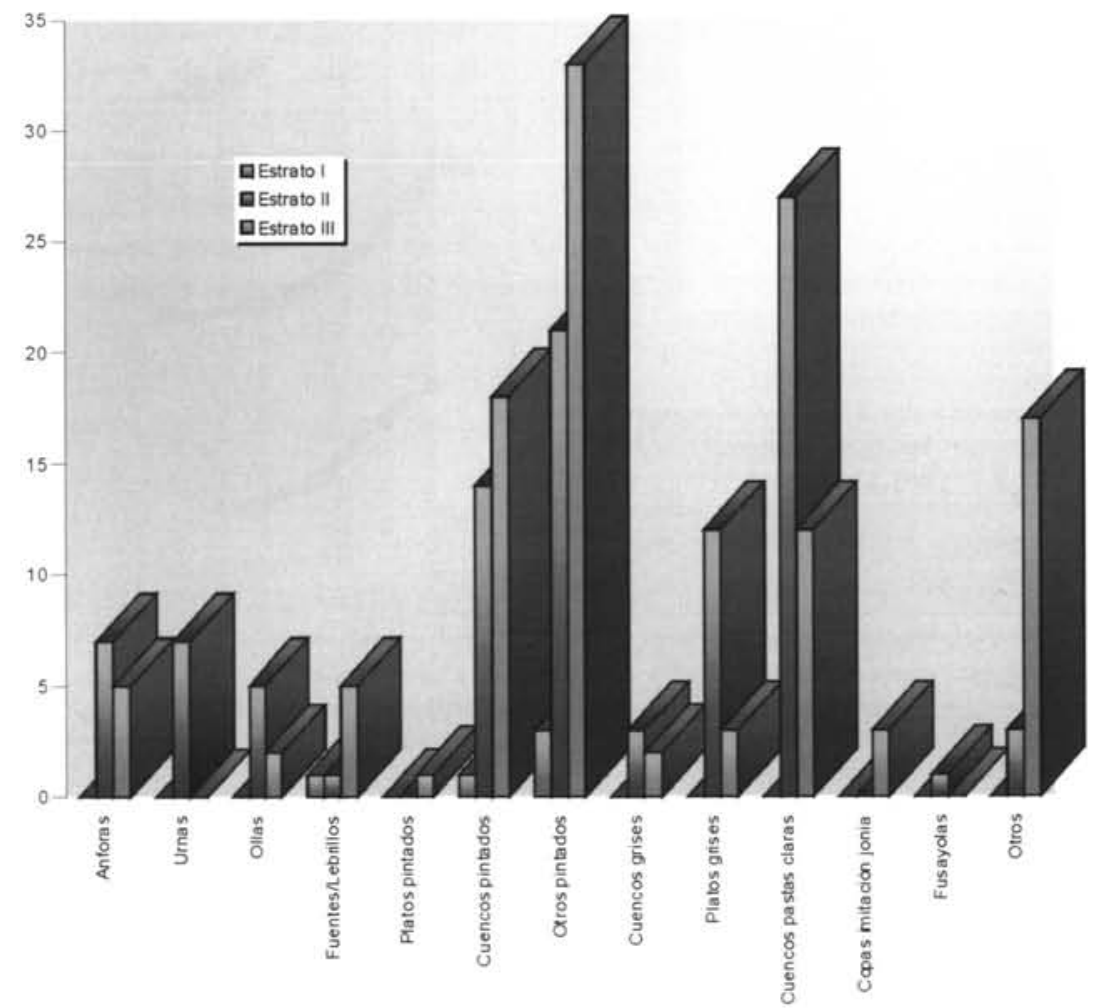

Gráfico 2. Proporciones de cerámicas a torno del corte C del Cerro Macareno. 